\title{
Structural and Mechanical Strength of Proton Radiation Processed Polyethylene Terephthalate
}

\author{
M. Sahoo ${ }^{1^{*}}$, B. Mallick ${ }^{2}$, S. Rout ${ }^{3}$ and G. N. Dash ${ }^{1}$ \\ ${ }^{1}$ School of Physics, Sambalpur University, Jyoti Vihar, Burla, Sambalpur 768019, India \\ ${ }^{2}$ Institute of Physics, Sachivalya Marg, Bhubaneswar 751005, India \\ ${ }^{3}$ Department of Physics, Odisha University of Agriculture and Technology, Bhubaneswar \\ 751003, India
}

Received 17 September 2019, accepted in final revised form 4 November 2019

\begin{abstract}
The change in structural and mechanical behavior of polyethylene terephthalate (PET) due to $2.4 \mathrm{MeV}$ proton has been studied. Radiation processing of PET polymer is carried out using different low doses such as $0.2,2.0$, and $20 \mathrm{kGy}$. The Physics of microstrain and radiation-induced mesophase formation are analysed. X-ray investigation indicates that proton-induced structural modification takes place in the material. Apart from usual diffraction peaks, a low intensity broad peak is observed at small angle of about $2 \theta$ $=10^{\circ}$, when the fibre axis is mounted parallel to the X-ray direction. Such peak is absent in the diffraction spectrum when the fibre axis is mounted perpendicular to the beam direction. The appearance of the extra peak in a particular orientation confirms that, the phase is 2-dimensionally oriented (mesophase). The Young's modulus $(Y)$ of this irradiated PET sample is found to be more than that of the virgin sample with the highest value recorded for a dose of $2.0 \mathrm{kGy}$. The decrease in $Y$ for higher dose ( $20 \mathrm{kGy}$ ) may be due to enhanced ion-induced microstrain in the sample, causing degradation in mechanical strength.
\end{abstract}

Keywords: Mesophase; Proton dose; Young's modulus; Microstrain.

(C) 2020 JSR Publications. ISSN: 2070-0237 (Print); 2070-0245 (Online). All rights reserved. doi: http://dx.doi.org/10.3329/jsr.v12i1.43168 J. Sci. Res. 12 (1), 83-91 (2020)

\section{Introduction}

In semi-crystalline polymers normally two phases exist namely crystalline and amorphous. But another phase is detected in the same polymer, when it is quenched from the melt [1]. This third phase of the polymer is called the mesomorphic phase or

*Corresponding author: himanu_nit@yahoo.co.in 
the mesophase which is intermediate between the crystalline and amorphous phase. It is a state of matter in which the degree of molecular order is intermediate between that of the perfect three dimensional, crystalline solids and that of the amorphous state. The study is important because, the mesomorphic phase has a reinforcement effect on the whole polymer matrix that leads to an increase in hardness with annealing of the oriented polymer [2]. Again, from the technological point of view, as the mesophase has proved impermeable to vapours at low activity, behaving like the crystalline phase, so the possibility of improving the impermeability of polyethylene terephthalate (PET) need to be explored for many applications $[3,4]$.

Existence of mesophase in polymers like PET, and polypropylene were confirmed using X-ray diffraction [5,6], solvent absorption [7], FT-Raman scattering [5], and nuclear magnetic resonance techniques [8] by various authors. However, protoninduced mesophase formation is a very recent work reported by Sahoo et al. [9,10].

In the present work, mesomorphic phase structure has been formed in the PET material by radiation heating process. The effect of fibre structure and its orientation due to different mounting have been studied using X-ray diffraction technique. The change in mechanical behavior of the fibre has also been studied due to formation of mesophase and total ion beam (IB) induced microstrain developed in the fibre using Instron technique. The study of $\mathrm{MeV}$ ion-induced modified polymer is very much interesting and important from technological point of view [11]. It is also observed that, the modification of polymer properties under ionizing radiation is a field of great interest due to its increasing uses in various fields [12,13]. Ionizing radiation can change the macroscopic properties and the molecular structure of polymeric materials [14]. The irradiated polymer possesses improved tensile strength, increased rigidity, improved yield strength, higher melting temperature and swelling in the usual solvent.

\section{Experimental}

\subsection{PET material}

PET material in the form of fibre used in the study was collected from a commercially available polyester plant. The molecular weight of repeated unit or monomer of PET is $192 \mathrm{~g} / \mathrm{mole} / \mathrm{unit}$ mer and having weight average molecular weight 25,330 (i.e., $\bar{M}_{w}=$ 25,330).

The three major processes used for the production of above PET fibre are esterification, polycondensation and spinning. In esterification process, mixture of purified terepthalic acid and ethylene glycol were used to produce oligomer. The above produced oligomer was passed through a 3-stage polycondensation reactor under various machine-setting parameters to produce viscous PET polymer. The above viscous polymer molten was again passed through a spinneret of very fine holes. While leaving the holes, the viscous material formed wire, which when passing through a heater and hot air produced long fibre filaments. 


\subsection{Proton irradiation}

A proton beam of energy $2.4 \mathrm{MeV}$ was obtained from the 9SDH-2, "National Electrostatic Corporation, USA make $3 \mathrm{MV}$ horizontal tandem type pelletron accelerator," to carry out ion irradiation in air. The PET fibre material was irradiated for three different low doses such as $0.2 \mathrm{kGy}, 2 \mathrm{kGy}$ and $20 \mathrm{kGy}$ at normal temperature and pressure in air. The amounts of charge trapped in the material for the above irradiations are $0.0048 \mu C, 0.048 \mu C$ and $0.48 \mu C$ respectively. The beam was initially collimated by a graphite collimator to a beam size of $3 \mathrm{~mm}$ diameter and was extracted into air using a Kapton ${ }^{\mathrm{TM}}$ foil of 8 micron at the exit point of the vacuum $\left(1 \times 10^{-6} \mathrm{mbar}\right)$ chamber. The diameter of the external proton beam may be increased up to $10-15 \mathrm{~mm}$ circular patch by proper adjustment. The external beam current measurement was performed using a rotating vane chopper designed at the Institute (Institute of Physics, Bhubaneswar). In the present study, initially $3 \mathrm{MeV}$ proton beam was allowed to travel $3 \mathrm{~cm}$ in air inside the irradiation cell (an aluminum cylinder of $15 \mathrm{~mm}$ diameter and $30 \mathrm{~mm}$ length) rotating with $1 \mathrm{~Hz}$ frequency for homogeneous irradiation, during which the energy of the proton beam gets reduced to $2.4 \mathrm{MeV}$ before interaction with the material.

\subsection{Sample Preparation}

The PET sample was mounted on a typical sample holder to form a flat sample of uniform length, breadth, thickness and well-parallelized bundle of filaments in each test sample for X-ray diffraction (XRD) investigation.

Furthermore, for the investigation of mechanical behavior, strips from the generalpurpose brown paper of area $80 \times 30 \mathrm{~mm}^{2}$ have been taken. From the center of the strip, a $20 \times 20 \mathrm{~mm}^{2}$ patch was taken out. Fibre of length $80 \mathrm{~mm}$ was initially fixed at the center of paper strip with the help of a suitable adhesive, which is non-reactive to the fibre. Again, another paper strip of the same type was fixed on the top of the fibre, so that the fibre should sit properly at the center of both the paper strips. The wellmounted dried sample was used for Instron study.

\subsection{Characterization}

We have carried out X-ray diffraction applying two orientation sample mounting procedure using "Rigaku Ultima-IV", X-ray diffractometer. As our interest is on mesophase analysis of PET sample, we preferred to mount the sample in two different ways, one is putting the fibre axis perpendicular to the beam direction and the other is putting it parallel to the beam direction. The X-ray diffraction patterns were recorded with a step size of $0.02^{\circ}$ on a $5^{\circ}-50^{\circ}$ range with a scanning rate of $0.34 \%$. Line focus $\mathrm{CuK}_{\alpha}$-radiation from an X-ray tube (operated at $40 \mathrm{kV}$ and $40 \mathrm{~mA}$ ) was collimated through Soller slit (SS) of $5^{\circ}$, fixed divergence slit of $0.67^{\circ}$ and mask $(8 \mathrm{~mm})$, before 
getting it diffracted from the sample. A D/teX ultra-high-speed position sensitive detector was mounted on the arm of the goniometer circle of radius $285 \mathrm{~mm}$ to receive diffracted X-ray signal, and analyzed using the integrated X-ray powder diffraction software PDXL 2.7.

The instrument used to study the tensile properties of PET fibre materials was a kmi UTM-201, electronic textile-testing machine which is commonly known as Instron (Kamal Metal Industries, India). Two numbers of strips from each PET polymer sample have been tested to find the average values of the mechanical parameters. The gauge length $(\mathrm{mm})$ for the test sample was taken to be $20 \mathrm{~mm}$. The load cell $(\mathrm{kg})$ was taken as 50 with load sensitivity of 02 . The test speed $(\mathrm{mm} / \mathrm{min})$ selected was 10 , however the maximum speed was set at $50 \mathrm{~mm} / \mathrm{min}$. The elongation least count was set at $0.025 \mathrm{~mm}$.

\section{Results and Discussion}

\subsection{IB Dose analysis}

The irradiated polymers is observed to possess mesophase which is improved compared to the 'virgin' material. The ratio of crosslinking and degradation depends on the chemical structure of a polymer and it is usually appraised by the radiationchemical yield or $G$-value of crosslinking which is defined as the number of chemical reactions or events occurs in the absorption of $100 \mathrm{eV}$ of radiation energy. For PET, the weight average molecular weight $\bar{M}_{w}$ and the radiation chemical yield $G(X)$ are given as 25,330 and 0.08 respectively $[15,16]$.

Hence, the dose required to convert maximum radiation-induced crosslink molecules in the above PET sample can be defined theoretically as: $D_{\text {rad }}=9.65 \times 10^{6} / G(X) \bar{M}_{w}$. Using the values of $G(X)$ and $\bar{M}_{w}, D_{r a d}=4.768 \times 10^{3} \mathrm{kGy}$. Again, the ion dose in terms of specific energy loss $\left(\frac{d E}{d x}\right)$ or stopping power and fluence $F$ can be defined as $D_{\text {rad }}=\left(\frac{d E}{d x}\right) F$. The value of $\left(\frac{d E}{d x}\right)$ for $2.4 \mathrm{MeV}$ proton in PET material is $1.864 \times 10^{8} \mathrm{eV} / \mathrm{cm}\left(1 \mathrm{~Gy}=1 \mathrm{~J} / \mathrm{kg}=6.289 \times 10^{18} \mathrm{eV} / \mathrm{kg}=8.786 \times 10^{15}\right.$ $\left.\mathrm{eV} / \mathrm{cm}^{3}\right)$. Hence, the ion-dose in terms of gray (Gy) can be calculated using the above conversion factor for the PET solid as $D_{\mathrm{rad}}=\frac{\left(1.864 \times 10^{8} \mathrm{eV} / \mathrm{cm}\right) \times F}{8.786 \times 10^{15} \mathrm{eV} / \mathrm{cm}^{3}}$. So, for a fluence of $1 \times 10^{10} \mathrm{p} / \mathrm{cm}^{2}$ in the present case, $D_{\text {rad }}=0.2122 \mathrm{kGy} \approx 0.2 \mathrm{kGy}$, this is the minimum radiation dose we have taken for the modification purpose. A maximum of $20 \mathrm{kGy}$ dose was used to modify the sample. 


\subsection{XRD analysis}

The PET fibre is mounted in two different orientations i.e., the X-ray beam parallel to the fibre axis, and the X-ray beam perpendicular to the fibre axis. The results are shown in the Fig. 1.

It is observed that, there is no distinct variation in $d$-spacing in either case of the mountings. Apart from the usual peaks, a low intensity broad extra peak is observed in the spectrum A (fibre axis parallel to the beam direction) of all cases of the fibres at small angles about $2 \theta=10^{\circ}$ as shown in Fig. 2 (extended version of a part of Fig. 1). Nonetheless, it is absent in the spectrum B (fibre axis perpendicular to the beam direction). This is implicative of the fact that when the fibre axis is parallel to the beam direction, nearly all the atoms of the oblique planes of the fibre helix participate in the diffraction. As a result, the 2-dimensionally ordered system formed by the atoms of the fibre helix produces prominent diffraction peaks owing to constructive interference of waves (mesophase). On the other hand, when the fibre axis is perpendicular to the beam direction, scattering from the mesophase does not produce prominent peaks because the effects are mutually cancelled out due to irregular distribution. The common peaks in both cases of the mounting indicate that the phases are 3dimensionally arranged. However the extra peak (mesophase) found in one orientation and not in other confirmed that, the given phase is 2-dimensionally oriented.
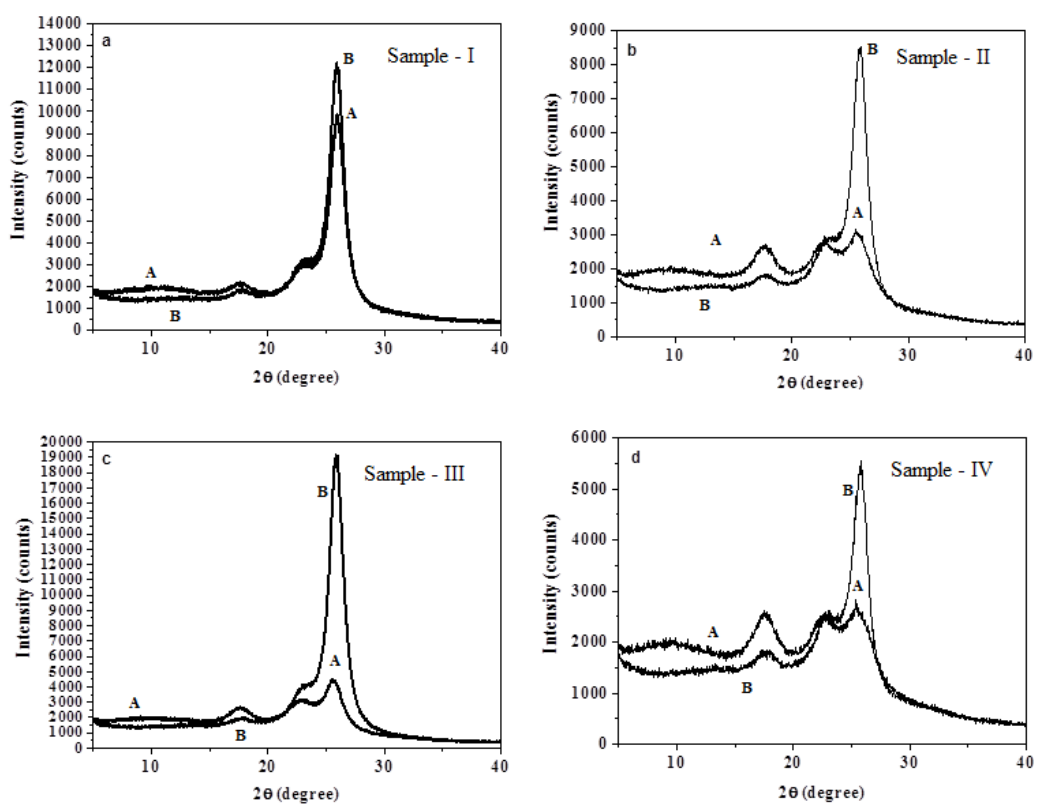

Fig. 1. X-ray diffraction pattern of PET fibre when the fibre axis is Parallel [A], and perpendicular $[\mathrm{B}]$ to the X-ray beam, (a) virgin sample, (b) sample irradiated at a dose $0.2 \mathrm{kGy}$, (c) sample irradiated at a dose $2 \mathrm{kGy}$, and (d) sample irradiated at a dose $20 \mathrm{kGy}$. 
The microstrain has been estimated using ${ }_{\varepsilon=\frac{\delta d}{d}}=\left(\frac{d_{s}-d_{u}}{d_{u}}\right)$, where $d_{s}$ and $d_{u}$ are the spacing in the irradiated (stressed) and non-irradiated (unstressed) fibres respectively. The value of total microstrain was calculated using the XRD data as shown in the Table 1. Among all the irradiated samples, the least value of total microstrain is developed in sample-III, which is found to be 0.055 . The highest value of total microstrain is found to be 0.135 in sample-IV. This maximum value of total ioninduced microstrain in sample-IV causes more degradation and less crosslink as compared to sample-III. The mesophase peaks of all the irradiated samples are observed to be shifted to the lower angles than the virgin, which is due to the ioninduced microstrain developed in the 2D-oriented surface of irradiated fibre.
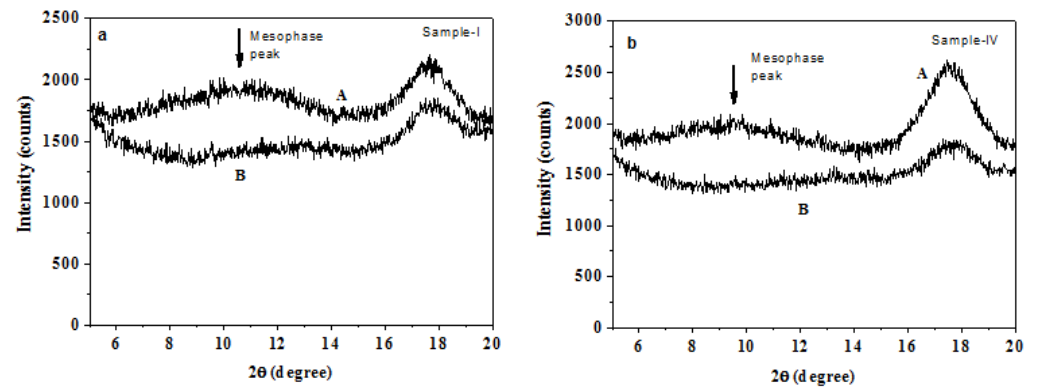

Fig. 2. Mesophase peak in the (a) virgin, and (b) sample irradiated at the highest dose.

Table 1. Microstrain by X-ray diffraction (Parallel mounting).

\begin{tabular}{|c|c|c|c|c|c|c|c|}
\hline Sample & $\begin{array}{c}2 \theta \\
(\text { deg. })\end{array}$ & $I_{p}($ cps $)$ & $d(\AA)$ & $\Delta d$ & $\varepsilon=\Delta d / d$ & Total $\varepsilon$ & $\%$ C \\
\hline I & 10.27 & 1942 & 8.606 & - & - & & \\
& 17.56 & 2122 & 5.048 & - & - & & 51.2 \\
& 23.10 & 2930 & 3.848 & - & - & & \\
& 25.97 & 9809 & 3.429 & - & - & & \\
\hline II & 9.14 & 1994 & 9.671 & 1.065 & 0.12 & & \\
& 17.56 & 2623 & 5.048 & - & - & 0.128 & 40.3 \\
& 22.79 & 2714 & 3.899 & 0.051 & 0.01 & & \\
& 25.53 & 3066 & 3.486 & 0.057 & 0.017 & & \\
\hline III & 9.84 & 1943 & 8.982 & 0.376 & 0.04 & & \\
& 17.64 & 2667 & 5.025 & -0.023 & -0.004 & & \\
& 22.84 & 3063 & 3.890 & 0.042 & 0.01 & 0.055 & 45.6 \\
& 25.70 & 4223 & 3.463 & 0.034 & 0.009 & & \\
\hline IV & 9.41 & 2011 & 9.394 & 0.788 & 0.09 & & \\
& 17.47 & 2540 & 5.073 & 0.025 & 0.005 & 0.135 & 41.7 \\
& 22.63 & 2516 & 3.926 & 0.078 & 0.02 & & \\
& 25.45 & 2743 & 3.498 & 0.069 & 0.02 & & \\
\hline
\end{tabular}

Again, the percent crystallinity $\% C$ has been calculated using the relation $\% C=\left(A_{\text {cryst }} / A_{\text {total }}\right) \times 100$, where $A_{\text {cryst }}$ and $A_{\text {total }}$ are total area of crystalline peaks and the diffraction pattern respectively. Percent crystallinity of virgin fibre has been 
found to be $51.2 \%$. However, the percent crystallinity of samples irradiated at different low doses were found to be less than the virgin sample. This is mainly because of the degradation of polymer and formation of proton-induced mesophase.

\subsection{Instron analysis}

Tensile properties of polymer are very important to understand the mechanical behavior. Radiation dose plays an important role for the modification of tensile strength and modulus of elasticity of polymer [17]. The Young's modulus or tensile modulus, which is a function of ultimate tensile strength (UTS) of the material has been estimated using the relation, $Y=\frac{U T S}{{ }_{\varepsilon} \text { Corr }}$, where $\varepsilon^{\text {Corr }}(=k \varepsilon, k$ is the correction factor and $\varepsilon$ is the engineering strain) is the corrected strain. Mechanical strength of the virgin and irradiated PET samples of fibre cross section area $0.625 \mathrm{~mm}^{2}$ can be analysed using Instron from the plots related to elongation versus load as shown in the Fig. 3. The various important parameters obtained experimentally are given in Table 2.
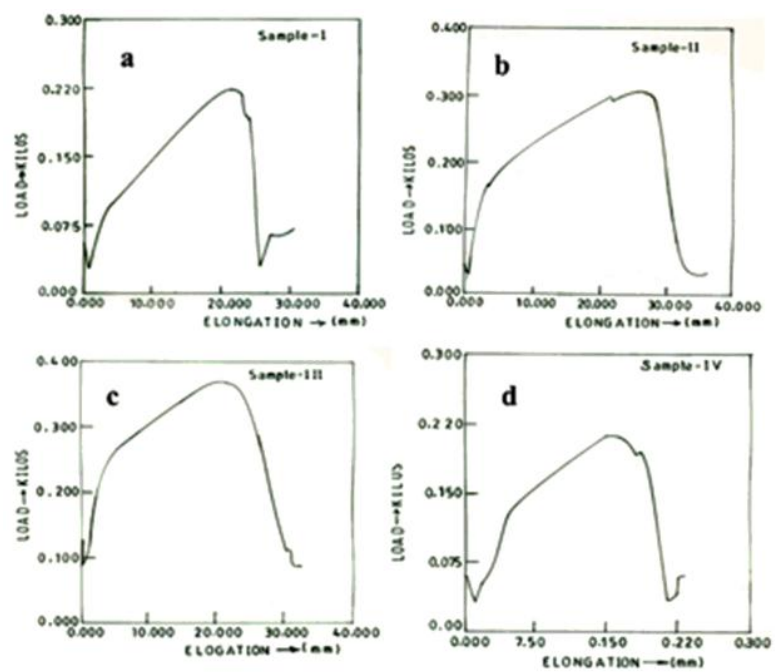

Fig. 3. Elongation versus load: (a) virgin sample, (b) sample irradiated at a dose $0.2 \mathrm{kGy}$, (c) sample irradiated at a dose $2 \mathrm{kGy}$ and (d) sample irradiated at a dose $20 \mathrm{kGy}$.

The Young's modulus $(Y)$ of virgin fibre is found to be $19.295 \mathrm{GPa}$. It is observed that the $Y$ value increases with increase in proton dose upto $2 \mathrm{kGy}$ (sample-III) and thereafter it decreases. But in any case it is found to be more than the virgin sample as shown in the Table 2. The highest value of $Y$ recorded is $38.425 \mathrm{GPa}$ in sample-III. Such observation is possibly due to lower value of radiation induced microstrain, that causes maximum crosslinking of molecules (as confirmed from the XRD). The decreased values of $Y(23.54 \mathrm{GPa})$ in case of fibre sample-IV (20 kGy) may be due to the formation of excessive ion-induced microstrain, which causes reduced crosslink 
and increased degradation as compared to sample-III (2 kGy). Higher value of the microstrain causes degradation in the mechanical strength of the fibre sample.

Table 2. Mechanical parameters of PET material.

\begin{tabular}{|c|c|c|c|c|c|c|c|c|c|}
\hline \multirow{2}{*}{$\begin{array}{l}\text { Samp } \\
\text { le }\end{array}$} & \multirow{2}{*}{$\begin{array}{l}\text { Dose } \\
(\mathrm{kGy})\end{array}$} & \multirow{2}{*}{$\begin{array}{l}\text { Max. } \\
\text { load } \\
(\mathrm{kg})\end{array}$} & \multirow{2}{*}{$\begin{array}{c}\text { Elong } \\
\text { ation } \\
\text { at } \\
\text { max. } \\
\text { load } \\
(\mathrm{mm})\end{array}$} & \multicolumn{2}{|c|}{$\%$ Elongation } & \multirow{2}{*}{$\begin{array}{c}\text { UTS } \\
\text { (MPa) }\end{array}$} & \multirow[t]{2}{*}{$\varepsilon^{\text {corr }}$} & \multirow{2}{*}{$\begin{array}{c}\mathrm{Y} \\
(\mathrm{GPa})\end{array}$} & \multirow{2}{*}{$\begin{array}{c}Y_{\text {avg. }} \\
(\mathrm{GPa})\end{array}$} \\
\hline & & & & $\begin{array}{l}\text { at } \\
\text { max. } \\
\text { load }\end{array}$ & $\begin{array}{c}\text { at } \\
\text { break }\end{array}$ & & & & \\
\hline I & 0 & $\begin{array}{l}0.4000 \\
0.3375\end{array}$ & $\begin{array}{l}15.98 \\
17.68\end{array}$ & $\begin{array}{l}79.88 \\
88.38\end{array}$ & $\begin{array}{l}134.75 \\
135.15\end{array}$ & $\begin{array}{l}62.78 \\
52.97\end{array}$ & $\begin{array}{l}0.003 \\
0.003\end{array}$ & $\begin{array}{l}20.93 \\
17.66\end{array}$ & 19.295 \\
\hline II & 0.2 & $\begin{array}{l}0.3688 \\
0.3938\end{array}$ & $\begin{array}{l}20.23 \\
23.27\end{array}$ & $\begin{array}{l}101.13 \\
116.37\end{array}$ & $\begin{array}{l}165.74 \\
180.62\end{array}$ & $\begin{array}{l}57.88 \\
61.80\end{array}$ & $\begin{array}{l}0.002 \\
0.002\end{array}$ & $\begin{array}{c}28.94 \\
30.9\end{array}$ & 29.92 \\
\hline III & 2 & $\begin{array}{l}0.4625 \\
0.3875 \\
\end{array}$ & $\begin{array}{l}19.35 \\
14.18 \\
\end{array}$ & $\begin{array}{l}96.75 \\
70.88 \\
\end{array}$ & $\begin{array}{l}162.22 \\
123.28 \\
\end{array}$ & $\begin{array}{l}72.60 \\
60.82 \\
\end{array}$ & $\begin{array}{l}0.002 \\
0.002\end{array}$ & $\begin{array}{c}36.3 \\
40.55 \\
\end{array}$ & 38.425 \\
\hline IV & 20 & $\begin{array}{l}0.3063 \\
0.2938\end{array}$ & $\begin{array}{l}14.95 \\
20.43\end{array}$ & $\begin{array}{c}74.75 \\
102.13\end{array}$ & $\begin{array}{l}114.61 \\
175.78\end{array}$ & $\begin{array}{l}48.06 \\
46.10\end{array}$ & $\begin{array}{l}0.002 \\
0.002\end{array}$ & $\begin{array}{l}24.03 \\
23.05\end{array}$ & 23.54 \\
\hline
\end{tabular}

\section{Conclusion}

Proton-induced mesophase formation in the PET polymer has been investigated with three different proton doses of irradiation. Structural change in the PET sample is analysed using XRD technique both at parallel and perpendicular mountings of the sample axis with respect to the X-ray beam. The common peaks in both the mounting indicated that the phases are 3-dimensionally arranged. However the extra peak (mesophase) found in parallel mounting confirmed that, the phase is 2-dimensionally oriented. The mesophase peak of all the irradiated samples is observed to shift towards the lower angles compared to the virgin sample, which might be due to the ion-induced microstrain developed in the $2 \mathrm{D}$-oriented surface of the irradiated fibre. The effect of ion-induced microstrain on mechanical strength is studied using the Instron technique. The Young's modulus $(Y)$ of all the irradiated samples are found to be more than that of the virgin sample. The present investigation will contribute greatly towards the study of mechanical strength of ion beam irradiated polymer materials and to understand various physical parameters of the materials.

\section{Acknowledgment}

We would like to thank Scientific and Technical staff of Ion Beam Laboratory, Institute of Physics, Bhubaneswar and Technical staff of Department of Metallurgical and Materials Engineering, NIT Rourkela for their help during experimental work.

\section{References}

1. T. Konishi, K. Nishida, G. Matsuba, and T. Kanaya, Macromolecules 41, 3157 (2008). https://doi.org/10.1021/ma702383b 
2. A. I. Abou-Kandil, A. Flores, F. J. B. Calleja, and A. H. Windle, J. Polym. Res. 15, 373 (2008). https://doi.org/10.1007/s10965-008-9181-7

3. F. de Candia, A. Ruvolo, and V. Vittoria, J. Macromol. Sci. Phys. B 31, 133 (1992). https://doi.org/10.1080/00222349208215508

4. F. de Candia, L. Guadango, and V. Vittoria, J. Macromol. Sci. Phys. B 34, 273 (1995). https://doi.org/10.1080/00222349508215535

5. A. Brookes, J. M. Dyke, P. J. Hendra, and S. Meehan, Spectrochimica Acta A 53, 2313 (1997). https://doi.org/10.1016/S1386-1425(97)00171-6

6. J. Wu and J. M. Schultz, Polymer 43, 6695 (2002). https://doi.org/10.1016/S0032$\underline{3861(02) 00672-9}$

7. A. Ruvolo-Filho and G. M. De Carvalho, J. Macromol. Sci. Phys. B 35, 255 (1996). https://doi.org/10.1080/00222349608212384

8. H. J. Biangardi, Prog. Colloid. Polym. Sci. 66, 99 (1979).

9. M. Sahoo, B. Mallick, G. N. Dash, and T. N. Tiwari, IOSR J. Appl. Phys. 7, 1 (2015).

10. M. Sahoo, B. Mallick, and G. N. Dash, Adv. Sci. Lett. 20, 838 (2014). https://doi.org/10.1166/asl.2014.5376

11. W. L. Brown, Nucl. Instrum. Methods Phys. Res. B 37/38, 270 (1989). https://doi.org/10.4006/1.3035879

12. G. Marletta, Nucl. Instrum. Methods Phys. Res. B 46, 295 (1990). https://doi.org/10.1016/0168-583X(90)90716-8

13. J. Davenas, I. Stevenson, N. Celette, S. Cambon, J. L. Garddette, A. Rivaton, and L. Vignoud, Nucl. Instrum. Methods Phys. Res. B 191, 653 (2002). https://doi.org/10.1016/S0168-583X(02)00628-6

14. D. Manas, M. Ovsik, A. Mizera, M. Manas, L. Hylova, M. Bednarik, and M. Stanek, Polymer 10, 158 (2018). https://doi.org/10.3390/polym10020158

15. A. P. Smith, R. J. Spontak, and H. Ade, Polym. Degrad. Stab. 72, 519 (2001). https://doi.org/10.1016/S0141-3910(01)00055-6

16. A. Licciardello, O. Puglisi, L. Calcagno, and G. Foti, Nucl. Instrum. Methods Phys.Res. B 46, 338 (1990). https://doi.org/10.1016/0168-583X(90)90724-9

17. M. M. Rahman, M. S. I. Mozumder, M. A. Islam, M. J. Uddin, M. A. Rashid, and M. E. Haque, J. Sci. Res. 3, 471 (2011). https://doi.org/10.3329/jsr.v3i3.3288 